\title{
Rasterstereography a reliable tool in scoliosis measurement - a critical review of literature
}

\author{
Narasimman Swaminathan*, Arun Mathew Cyriac, Michelle E Lobo \\ From 11th International Conference on Conservative Management of Spinal Deformities - SOSORT 2014 \\ Annual Meeting \\ Wiesbaden, Germany. 8-10 May 2014
}

Measuring the structural deformities of the spine is always a challenge for the clinician, since it is important to make clinical decision. When repeated exposure to the $\mathrm{X}$ ray has to be reduced in the routine practice, rehabilitation professionals are looking for a tool to be used in daily practice. Rasterstereography is one such method used from the early of 1980s attracted the attention of clinician in the western world. Recently it has been introduced to the developing countries like India. In this context it is important to analyse the available evidence pertaining to rasterstereography.

\section{Aim}

The aim of this paper is to review the available published papers and critically analyse the results in terms of reliability, validity and clinical use of this tool.

\section{Method}

A structured literature review was done in PubMed, Ovid, Embase and CINHAL data base using rasterstereography, scoliosis and spine measurement as key words. Boolean logic was used to combine and restrict the results. The articles were restricted to English language. All the articles were appraised by the authors independently by using a predetermined review sheet, which consisted of details including population studied, number subjects, study method, statistical analysis used, results and critical view of the authors.

\section{Results}

20 articles were identified after the search, of which $7 \mathrm{stu}$ dies used rasterstereography in scoliosis population. There are studies which compared the rasterstereography with gold standard radio graphic measurement. Results of the

Father Muller Medical College, Mangalore, India high quality studies explored the utility of this tool in the evaluation of the scoliosis. This paper will discuss the advantages and challenges of using this tool in daily clinical practice.

\section{Conclusion}

This critical review identifies the advantages of rasterstereography in scoliosis assessment and the future direction in using this novel too in the diagnosis and the management of scoliosis.

Published: 4 December 2014

doi:10.1186/1748-7161-9-S1-05

Cite this article as: Swaminathan et al:: Rasterstereography a reliable

tool in scoliosis measurement - a critical review of literature. Scoliosis 2014 9(Suppl 1):05.
Submit your next manuscript to BioMed Central and take full advantage of:

- Convenient online submission

- Thorough peer review

- No space constraints or color figure charges

- Immediate publication on acceptance

- Inclusion in PubMed, CAS, Scopus and Google Scholar

- Research which is freely available for redistribution
() Biomed Central 